\title{
Postseismic deformation and the strength of ductile shear zones
}

\author{
Laurent G. J. Montési \\ Woods Hole Oceanographic Institution, Department of Geology and Geophysics, Woods Hole, MA 02543, USA
}

(Received May 28, 2004; Revised August 31, 2004; Accepted September 21, 2004)

\begin{abstract}
A good understanding of the rheology and strength of the whole crust is needed to obtain a physics-based earthquake prediction models. However, geodynamics-based and laboratory-based strength estimates disagree. Geodynamics tend to indicate that the actual strength of the plastic crust is less than deduced from laboratory experiments. Here, I evaluate lower crust strength from observations of transient postseismic deformation. Fault motion during an earthquake produces only a small stress perturbation, but that perturbation is sufficient to significantly affect the deformation rate of the aseismic levels of the crust, as observed by space geodesy. Even considering the non-linearity of plastic flow in geological materials, one cannot escape the conclusion that the pre-earthquake stress on the region where transient postseismic deformation occurs is not more than an order of magnitude larger than earthquake-induced stress perturbations. Using a simple shear zone model and assuming wet quartzite rheology, I show that such stress levels are not compatible with a km-scale shear zone, in spite of the geological evidence for localized deformation in the plastic crust. This implies that in plastic shear zones, rock strength is reduced. Possible explanations for the strength reduction include structural effects such as reduced grain size and/or a localized thermal anomaly associated with the shear zone.
\end{abstract}

Key words: Shear zones, strength, postseismic deformation, rheology.

\section{Introduction}

In order to better assess earthquake risks, it is necessary to have a good understanding of the structure and mechanics of the crust in both the brittle and plastic regimes. For instance, ductile flow in the lower crust has been shown to influence earthquake triggering in Southern California (Freed and Lin, 2001). Numerical models indicate the possible presence of earthquake precursors generated in the transition zone between brittle and plastic regimes (Shibazaki et al., 2002). Such precursors may have been observed geodetically (Iio et al., 2002).

To evaluate whether the plastic lower crust plays the role of the mythical Namazu, the catfish below the Japanese islands whose shaking produces earthquakes and tsunamis, we need well-constrained constitutive laws for the plastic crust. However, most laws used in literature have been derived from laboratory experiments and extrapolated to natural conditions. This approach leaves open the possibility that an unrecognized deformation regime invalidates the flow laws at large scale (e.g., Paterson, 1987). The arrangement of plastic flow in localized shear zones, which is not observed in the laboratory, may be such an unaccounted-for large scale flow regime. Thus, it is critical to test rheological laws using natural phenomena. Postseismic deformation has the potential to provide the means of probing plastic flow in the actively deforming aseismic lower crust.

Postseismic deformation is observed in the immediate aftermath of an earthquake. Dominantly aseismic, it is

Copy right(c) The Society of Geomagnetism and Earth, Planetary and Space Sciences (SGEPSS); The Seismological Society of Japan; The Volcanological Society of Japan; The Geodetic Society of Japan; The Japanese Society for Planetary Sciences; TERRAPUB. most evident in geodetic datasets. Recently, space geodetic techniques, and in particular continuous Global Positioning System have returned a great wealth of details concerning postseismic deformation (Heki et al., 1997; Bürgmann et al., 2002). It is now evident that postseismic deformation comprises several distinct phenomena, including poroelastic rebound (Peltzer et al., 1996; Jónsson et al., 2003), frictional afterslip (Marone et al., 1991), and accelerated plastic flow (Thatcher, 1983). The time dependence of postseismic deformation requires a nonlinear rheology, which reveals the importance of plastic flow mechanisms in the postseismic time interval (Freed and Bürgman, 2004; Montési, 2004). All these phenomena are consequences of the stress perturbations resulting from seismic motion. As transient postseismic deformation reflects the response of a portion of the crust to a stress perturbation, it can be used to infer the rheology of the region being activated.

Although postseismic deformation includes several different phenomena, GPS data collected in a distributed network appear most sensitive to deformation in the down-dip continuation of seismogenic faults (Peltzer et al., 1998), that I refer to in this paper as postseismic creep. This is because deformation processes occurring at shallower levels, such as poroelastic rebound produce a signal that is localized near the fault trace (Freed and Bürgmann, 2004). By contrast, differentiating using surface measurements only between distributed and localized deep deformation is inherently difficult and downright impossible for infinitelylong strike-slip ruptures (Savage, 1990). Nevertheless, the GPS-determined pattern of crustal motion in the aftermath of several recent earthquakes is well explained by displacement on a localized shear zone in the depth-continuation of 
the seismogenic fault. For instance, after the 1999 Izmit (Turkey) earthquake, Bürgmann et al. (2002) document slip occurring in two main patches, one located at $\sim 15 \mathrm{~km}$ depth below the epicenter, the other at $35 \mathrm{~km}$ depth at a kink in the fault trace. Yagi et al. (2003) also document postseismic deformation in the area downdip of the 1994 SanrikuHaruka-Oki rupture. In summary, recognizing the inherent non-uniqueness of inversion results, it is at least possible that transient postseismic deformation observed by GPS occurs in a localized shear zone below the seismogenic zone.

Although laboratory experiments indicate that deformation should cease to be localized below the seismogenic zone, many geological and geophysical data indicate the presence of localized shear zones in that depth range (e.g., Ramsay, 1980; Vauchez and Tommasi, 2003). For instance, the seismicity cutoff around the Nojima fault is consistent with the rheology of wet granite deforming at $10^{-13} \mathrm{~s}^{-1}$, which indicate localized deformation (Iio and Kobayashi, 2002). However, because of the uncertainties in their strength and rheology, it is debatable whether localized plastic shear zones play an important role in largescale tectonics. The main goal of this publication is to test whether shear zone behavior extrapolated from the laboratory is compatible with the magnitude of transient postseismic deformation.

Shear zones are visible in the field as regions of higher strain than the surrounding host rock. Their width ranges from a few millimeters to a couple of kilometers. They may be marked by reduced grain size or a different metamorphic assemblage than the host rock. The presence of enhanced deformation probably reflects the lower strength of these rocks, which may be due to the structural effects noted above or to an associated thermal anomaly where the shear zone is hotter than its surroundings (Hobbs et al., 1990; Montési and Zuber, 2002; Regenauer-Lieb and Yuen, 1998, 2003). Using postseismic deformation to estimate the strength of localized plastic shear zones can lead to better constraints on the origin of their weakness.

Stress perturbations produced by an earthquake are expected to be of the order of the stress drop. This value, as determined by seismology, is often low, at most $10 \mathrm{MPa}$ (e.g., Kanamori and Anderson, 1975; Hanks, 1977). In contrast, the strength of the plastic rocks can exceed several $100 \mathrm{MPa}$ (e.g., Carter and Tsenn, 1987; Kohlstedt et al., 1995). This discrepancy is exacerbated if one realizes that earthquake-induced stress changes decrease rapidly with distance away from the fault. Hence, we are faced with a important conceptual problem: How can an earthquake, with such small stress perturbations, affect flow in the plastic regime? In this study, it will become evident that there is not a single number that can describe plastic strength and stress perturbations. Both the stress perturbation and plastic strength decrease with depth. The question then becomes: which decays most rapidly with depth.

In the next section, I will show how the observed postseismic signals can be used to constrain shear zone strength. Then, I will present several models of localized shear zones based on the rheology of quartzite determined from laboratory experiment that imply strength reduction of the shear zone. Finally, I will discuss the origin of this strength reduc- tion and its relation with microstructural evidence for high stress in plastic shear zones.

\section{From Postseismic Creep to Shear Zone Strength}

\subsection{Changes in shear zone velocity}

Geodetic data indicate that the crust is deforming aseismically in the pre-earthquake time interval below a certain locking depth at a rate similar to the long-term fault slip rate. The aseismic deformation rate is significantly higher after the earthquake, which leads to measurable postseismic signals. In the case of the 1999 Izmit (Turkey) earthquake, pre-earthquake GPS data as well as geological studies indicate a long-term displacement rate of $V_{i} \sim 2.5 \mathrm{~cm} / \mathrm{yr}$ (Ambraseys, 2002; McClusky et al., 2000). Immediately after the event, the inferred shear zone velocity $V_{p s}$ is up to $2 \mathrm{~m} / \mathrm{yr}$ (Bürgmann et al., 2002). In this example, the ratio of velocities before and after the earthquake $R_{V}=V_{p s} / V_{i}$ approaches 100 .

To infer shear zone strength, we need to estimate the velocity ratio of the aseismic shear zone. In the case of Izmit, the presence of a network of continuously operating GPS stations makes it possible to invert kinematically for shear zone velocity, giving good constraints on $R_{V}$. In other cases, such data is not available. Nevertheless, data from a single station provide a lower bound for $R_{V}$. The change of velocity of the GPS station $R_{G P S}$ is the convolution of the spatially variable real change in velocity and the sensitivity kernel of the station. If the detected deformation is generated roughly in the same area before and after the earthquake, $R_{V} \sim R_{G P S}$. Otherwise, the postseismic signal comes from a region where interseismic slip was not resolved, and $R_{V}>R_{G P S}$.

Because postseismic creep relaxes the earthquakeinduced stress perturbation, the shear zone velocity decreases with time and approaches asymptotically the interseismic rate. This is now very well documented using continuous GPS, which provides a record of postseismic motion with high temporal resolution. It is therefore important to consider the velocity determined as soon as possible after the earthquake if one aims at studying the effects of earthquakes on shear zone dynamics. Every estimate made over more than a few days underestimates the initial postseismic velocity and therefore $R_{V}$.

Beyond the example of the Izmit earthquake discussed above, many events have produced acceleration of nearby geodetic station by at least an order of magnitude. To cite only a few of the best studied events, good records are available for the 1994 Sanriku-Haruka-Oki earthquake (Heki et al., 1997; Yagi et al., 2003), the 1997 Kronotsky event (Bürgmann et al., 2001), the 1999 Chi-Chi earthquake (Hsu et al., 2002; Yu et al., 2003), the 1999 Hector Mine earthquake (Hudnut et al., 2002), the 2001 Peru earthquake (Melbourne et al., 2002), and the 2003 Denali event (Freymueller et al., 2002). It can even be argued that for a clear postseismic signal to be detected in continuous GPS, the station velocity immediately after the earthquake must differ from pre-earthquake velocity by at least a factor of 10 . Modeling the time decay of several of these events, Montési (2004) also finds a factor of 10 difference between the ve- 
locity immediately after the event and the asymptotic velocity.

In summary, geodetic data strongly suggest that for many events, $R_{V} \geq 10$. This does not imply that every earthquake produces such changes in aseismic deformation rate, but at least in some case, the structure and strength of the lithosphere is such that the deformation rate of some aseismic region increases by at least a factor of 10 as a consequence of an earthquake.

\subsection{Inference of shear zone strength}

If we follow the geological evidence that plastic creep occurs in localized shear zones in the down-dip continuation of brittle faults, the relation between shear zone velocity $V_{S}$ and the deviatoric stress $\sigma$ on it is generally given by

$$
V_{S}=H A f_{H_{2} O}^{m} \exp (-Q / R T) \sigma^{n}
$$

where $H$ is the thickness of the shear zone, $T$ the temperature, $f_{\mathrm{H}_{2} \mathrm{O}}$ the water fugacity, $A$ the pre-exponential factor, $n$ the stress exponent, $m$ the water fugacity exponent, $Q$ the activation energy, and $R$ the gas constant. (e.g., Evans and Kohlstedt, 1995). Alternative formulae may be appropriate at lower temperature or high stress, and additional dependencies on mineralogy, oxygen fugacity and grain size are possible. However, postseismic creep is observed over a wide depth range (e.g., Bürgmann et al., 2002). Equation (1) is the most likely flow law a few kilometers below the rupture zone.

The constitutive parameters $A, m, n$, and $Q$ have been studied in the laboratory for many rock types (e.g., Carter and Tsenn, 1987; Evans and Kohlstedt, 1995). Hirth et al. (2001) calibrated the flow law for quartzite using both laboratory experiments and microstructural investigation of a naturally-deformed quartzite. This flow law is one of the most relevant flow laws for plastic flow of the crust and will be used for the remainder of this work. The parameters used in this study are in fact adapted from the published values to reflect the different loading geometry in the laboratory and in nature. In particular, in this study, the stress in Eq. (1) is defined as the deviatoric shear stress on a vertical strike-slip shear zone.

If the supposed shear zone deforms at the rate $V_{S}$ under an applied stress $\sigma$, it is appropriate to call $\sigma$ the strength of the shear zone. Before an earthquake, the shear zone can therefore be assumed to have strength $\sigma_{i}$ and to deform at a rate $V_{i}$ whereas after an earthquake, its strength is $\sigma_{i}+\Delta \sigma$ and its velocity $V_{p s}$, where $\Delta \sigma$ is the earthquake-induced stress perturbation on this shear zone. From the functional form of Eq. (1), it is straightforward to convert the ratio $R_{V}=V_{p s} / V_{i}$ into a strength ratio

$$
R_{S}=\sigma_{i} / \Delta \sigma=\left(R_{V}^{1 / n}-1\right)^{-1} .
$$

Figure 1 depicts this relation for several values of $n$. Most geological materials have $n$ between 3 and 5. In particular, for the quartzite rheology of Hirth et al. (2001), $n=4$. It appears that if $R_{V} \geq 10, R_{S}$ is at most 10 , and possibly less than 0.1 . A lower bound on $R_{V}$ translates into an upper bound on $R_{S}$. If we can estimate $\Delta \sigma$ from the earthquake slip distribution, we can construct an estimate of $\sigma_{i}$.

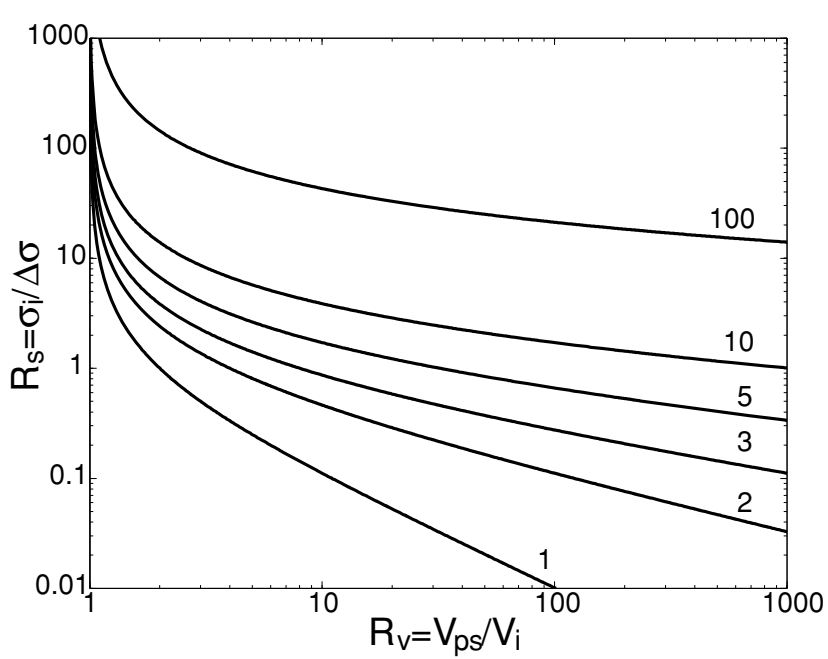

Fig. 1. Shear zone strength $\sigma_{i}$ scaled by the earthquake-induced stress perturbation $\Delta \sigma$ deduced from the change of shear zone velocity from $V_{i}$ before the earthquake to $V_{p s}$ immediately after the event. Each curve is labeled with the stress exponent used in the power law relationship.

\section{Comparison with Quartzite Flow Laws}

The reasoning outlined above implies that interseismic shear zone strength is at most an factor of 10 larger, and probably much less, than earthquake-induced perturbations. As they scale with the stress drop, earthquake-induced stress perturbations are small. Therefore, it is important to evaluate whether this strength ratio is reasonable or not. Certainly, one must keep in mind that both shear zone strength and earthquake-induced stress perturbations decrease with depth. The relation $R_{s}=\sigma_{i} / \Delta \sigma \leq 10$ is not necessarily verified at all depth range: regions where $R_{s}>10$ simply do not contribute to the observed postseismic signal. Therefore, in this section, I estimate shear zone strength using a quartzite rheology and stress perturbation for typical large earthquake parameters to estimate at what depth range shear zone strength is less than an order of magnitude greater than earthquake-induced stress changes. As it is commonly held that shear zone strength is much larger than earthquake stress drop, my parameter choices are aimed at maximizing earthquake-generated stress perturbation and minimizing shear zone strength estimates.

\subsection{Magnitude of earthquake-induced stress perturba- tions}

The sudden motion of a fault during an earthquake perturbs the state of stress of the crust. Elementary dislocation theory can be used to calculate the magnitude of the stress perturbation produced by motion on a fault patch of any geometry in an elastic half-space (e.g., Okada, 1992). For simplicity, I consider here only the case of an infinitely long vertical strike-slip fault. The fault ruptures the depth interval $z=0$ to $D$ and is located at $x=0$. Assuming uniform slip of magnitude $U$ and a shear modulus for the half-space $G$, fault motion induces a stress perturbation

$$
\Delta \sigma_{x y}=G U\left\{\begin{array}{r}
\frac{1}{2 \pi}\left[\frac{z-D}{x^{2}+(z-D)^{2}}-\frac{z+D}{x^{2}+(z+D)^{2}}\right] \\
+\delta(x) \mathcal{H}(D-z)
\end{array}\right\},
$$


Table 1. Stress perturbation profile on a vertical shear in the downdip continuation of a strike-slip fault due to various slip distribution on the fault.

\begin{tabular}{|c|c|c|}
\hline Type & slip distribution $U(z) / \bar{U}$ & Stress perturbation profile $\Delta \sigma(z) / \frac{G \bar{U}}{\pi D}$ \\
\hline Uniform & 1 & {$\left[(z / B)^{2}-1\right]^{-1}$} \\
\hline Linear & $2(z / D)$ & $2\left[(z / B)^{2}-1\right]^{-1}+\log \left[1-(D / z)^{2}\right]$ \\
\hline Linear & $2-2(z / D)$ & $-\log \left[1-(D / z)^{2}\right]$ \\
\hline Bilinear & $\begin{array}{cl}4(z / D) & \text { if } 0<z<D / 2 \\
4-4(z / D) & \text { if } D / 2<z<D\end{array}$ & $2 \log \frac{\left[(z / D)^{2}-1 / 4\right]^{2}}{(z / D)^{4}-(z / D)^{2}}$ \\
\hline Quadratic & $6(z / D)-6(z / D)^{2}$ & $-12+6 \frac{z}{D} \log \frac{z / D+1}{z / D-1}+3 \log \left[1-(D / z)^{2}\right]$ \\
\hline Cubic & $12(z / D)-24(z / D)^{2}+12(z / D)^{3}$ & $30+24 \frac{z}{D} \log \frac{z / D+1}{z / D-1}+6\left[3(z / D)^{2}+1\right] \log \left[1-(D / z)^{2}\right]$ \\
\hline
\end{tabular}

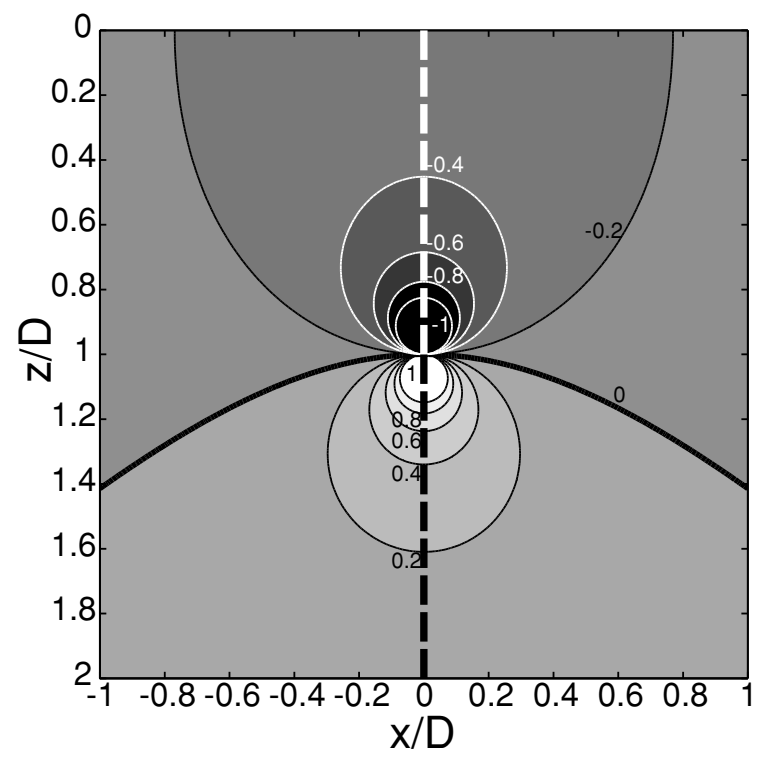

Fig. 2. Magnitude of stress perturbation on a vertical shear zone (dashed black line) due to an earthquake on a vertical strike-slip fault (dashed white line). The black dashed line indicates the down-dip continuation of the seismogenic fault, where stress perturbations are maximum. All distances are scaled by the depth to the fault, $D$, and the stress perturbation is scaled by $\frac{G U}{\pi D}$ where $G$ is the shear modulus and $U$ is the coseismic displacement.

$$
\Delta \sigma_{z y}=G U\left\{\begin{array}{r}
\frac{x}{2 \pi}\left[\frac{1}{x^{2}+(z-D)^{2}}-\frac{1}{x^{2}+(z+D)^{2}}\right] \\
+\frac{x}{|x|} \delta(z)
\end{array}\right\},
$$

where $\delta(x)$ is the Dirac distribution and $\mathcal{H}(D-z)$ is the Heavyside function.

$\Delta \sigma_{x y}$ indicates the change of shear stress on a vertical shear zone. This is the quantity that produces postseismic deformation in this configuration. Its distribution is shown in Fig. 2. At each depth, the maximum stress perturbation is at $x=0$, i.e., in the downdip continuation of the fault. Hence, the location where postseismic deformation is most efficiently generated is in a vertical shear zone below the seismogenic fault. For the remainder of this work, I will use only estimates of stress perturbations at $x=0$, although this overestimates the stress change on a shear zone of finite thickness. With this simplification, Equation (3) becomes

$$
\Delta \sigma=\frac{G}{\pi} \frac{U / D}{(z / D)^{2}-1} .
$$

In the two-dimensional model adopted here, the char-

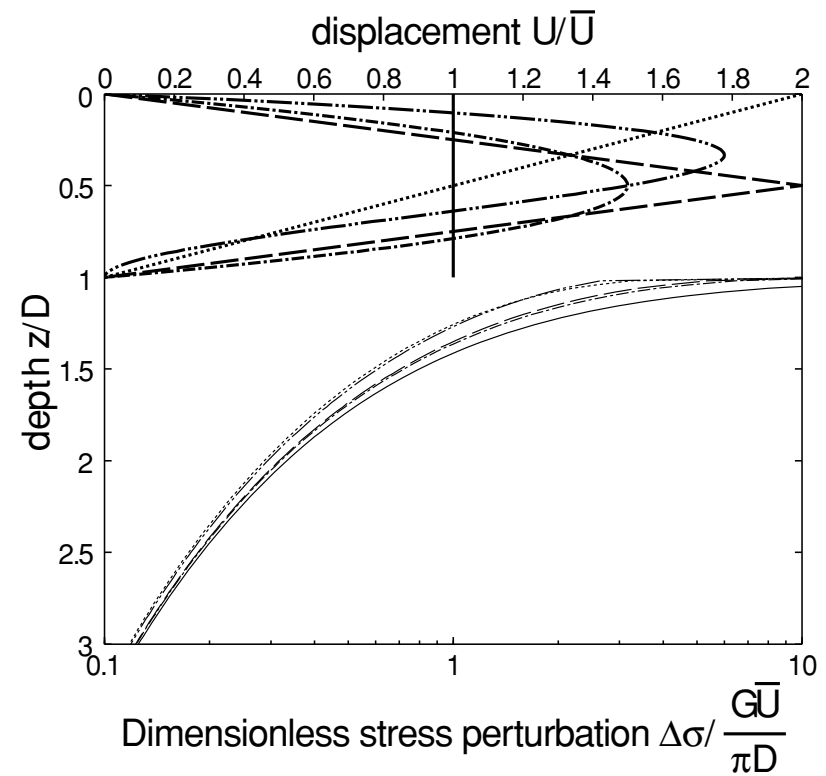

Fig. 3. Profiles of stress perturbation (thin lines) on a vertical shear zone due to different slip distributions (thick lines) on a seismogenic fault. Geometry as in Fig. 2. Linestyle indicates slip distribution: uniform (solid lines); linear (dotted line); bilinear (dashed line); quadratic (dash-dots); cubic (dash-double dot).

acteristic length scale of the rupture is the depth range of the rupture, $D$. Hence, the stress drop is defined as $\delta \sigma=G U / D$. As may be expected, the stress perturbation scales with the stress drop of the earthquake. However, Equation (5) reveals that $\Delta \sigma$ is a strong function of depth.

To evaluate how alternative slip distributions affect stress perturbation estimates, I generalize Eq. (5) for a spatially varying slip distribution $U(D)$ in the depth range $D_{A}<$ $D<D_{B}$

$$
\Delta \sigma=\frac{G}{\pi} \int_{D_{A}}^{D_{B}} \frac{U\left(z^{2}+D^{2}\right)}{\left(z^{2}-D^{2}\right)^{2}} d D .
$$

Table 1 gives the expressions of $\Delta \sigma$ for various assumptions on $U(D)$. In these expressions $D_{A}=0$ and $D_{B}=D$. For scaling purposes, each slip distribution has the same average slip $\bar{U}$. The expected depth-distribution of stress perturbations are shown in Fig. 3. It appears that except in the immediate vicinity of the fault rupture, there is less than a factor of two difference between the stress perturbations for different slip distributions. However, no estimate should be trusted within a few $\mathrm{km}$ of the earthquake rupture. Fig- 
ure 3 also brings home the point that it is difficult to give a single number for the earthquake-induced stress perturbation, as $\Delta \sigma$ varies by more than an order of magnitude over the depth interval considered. Instead, the depth-dependent expression for $\Delta \sigma$ must be considered.

For all the slip distributions considered here, the stress perturbation is infinite at $z=D$, a common occurrence in crack models. In reality, the stress singularity induces yielding, which tends to propagate the rupture into the plastic lower crust, modifies the stress perturbation field and tapers the tip of the slip distribution (e.g., Ida, 1972; Cowie and Scholz, 1992). Although it is possible to derive expressions for the stress perturbation that take into account yielding at the edge of the rupture, they rely on imposing a predefined length of the breakdown region or a limiting stress. Hence, the earthquake-induced stress perturbation near the brittleductile transition remains uncertain. For simplification, I will ignore the effects of yielding. In the same spirit, I also ignore the effects of highly heterogeneous slip distribution which characterizes many large earthquakes. It is expected that these processes have little effect on the stress perturbation beyond a few $\mathrm{km}$ of the rupture edges.

\subsection{Strength of quartzite shear zones}

The strength of plastic shear zones is depth-dependent as well, through the temperature profile $T(z)$ in Eq. (1). For generality, I assume a conductive temperature profile parameterized by the surface geotherm $d T /\left.d z\right|_{z=0}$ and the asymptotic temperature $\left.\lim (T)\right|_{z \rightarrow \infty}=1350^{\circ} \mathrm{C}$. Shear zone strength also depends on thickness, a highly uncertain parameter. Therefore, I present shear zone strength in Fig. 4(A) as a function of shear zone thickness $H$ and depth $z$. In the reference case (Fig. 4), I use the quartzite rheology of Hirth et al., (2001) and a surface geotherm of $20 \mathrm{~K} / \mathrm{km}$. The geotherm is meant to represent a "typical" crustal geotherm and the rheology one of weakest rock types relevant for the crust at large scale. Water fugacity in Eq. (1) is function of pressure and temperature. I follow the water fugacity table of Tödheide (1972), thereby obtaining strength estimates for water-saturated conditions. Once again, my purpose in following these assumptions is to obtain a minimum estimate of shear zone strength, which presents the best chance of verifying $R_{S} \leq 10$.

In Fig. 4, I also report the predicted depth of the brittleductile transition, defined as the point where shear zone strength equals the frictional resistance of a brittle fault assuming a strike-slip environment and hydrostatic fluid pressure (e.g. Brace and Kohlstedt, 1980). Although the transition from brittle to fully plastic behavior is expected over a wider depth range than considered here, this approach produces a good first estimate of the downward limit of earthquakes. Above this level, shear zones strength is unlikely to obey Eq. (1).

\subsection{Minimum shear zone thickness}

The simple shear zone model presented above predicts strengths in excess of $200 \mathrm{MPa}$ near the brittle-ductile transition, decaying rapidly to only a few MPa. Narrower shear zones result in higher strength, making is less likely that earthquakes have a strong effect on narrow plastic shear zones. Therefore, there is a minimum shear zone thickness $H_{m}$ for which the observed magnitude of postseismic creep
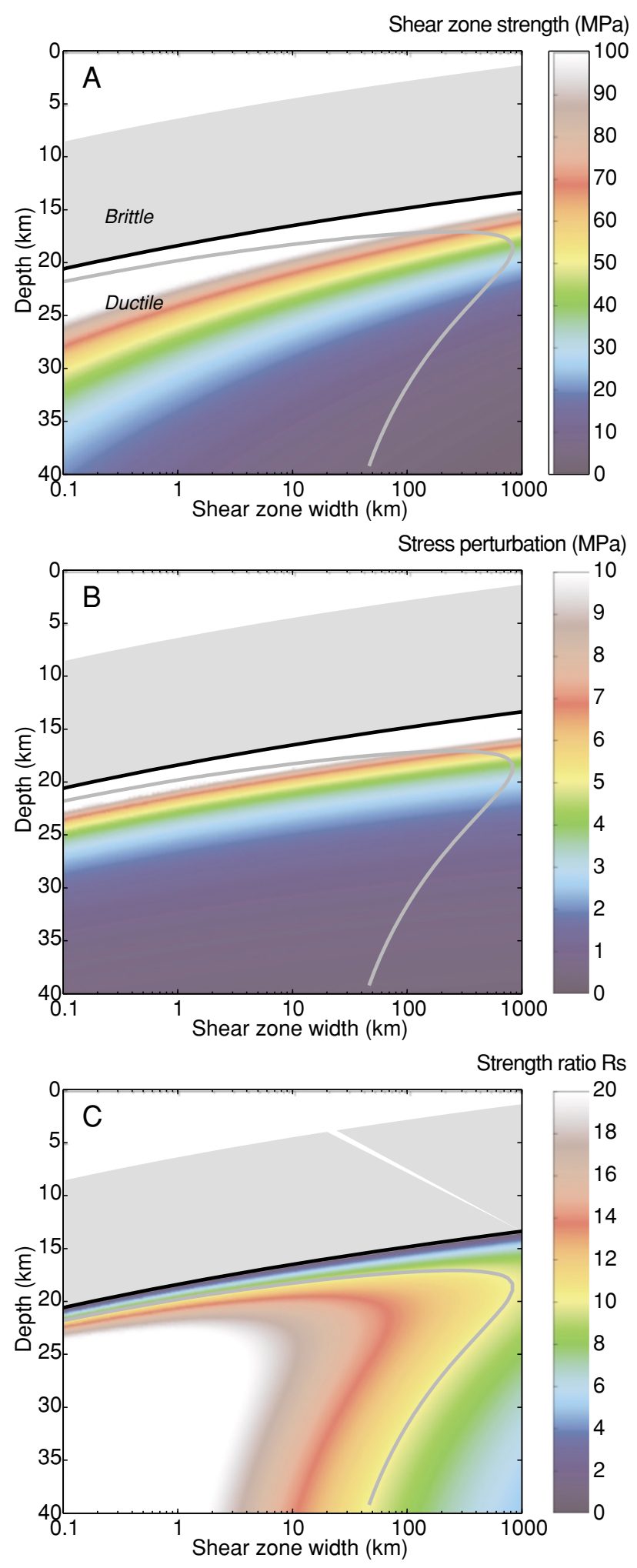

Fig. 4. (A) Shear zone strength $\sigma_{i}$, (B) Earthquake induced stress perturbation $\Delta \sigma$, and (C) strength ratio $R_{S}=\sigma_{i} / \Delta \sigma$ as a function of shear zone width $H$ and depth. The shear zone deforms at velocity $V_{S}=25$ $\mathrm{mm} / \mathrm{yr}$ before the earthquake, and obeys the quartzite rheology of Hirth et al. (2001). The surface geotherm is $20 \mathrm{~K} / \mathrm{km}$. The shear modulus is $5 \times 10^{10} \mathrm{~Pa}$. The earthquake ruptures the $12 \mathrm{~km}$ above the expected brittle-ductile transition with uniform slip of $3 \mathrm{~m}$. In each graph, the grey area indicates the depth range of the earthquake rupture, the solid back line marks the brittle-ductile transition, and the solid grey line indicates the conditions for which $R_{S}=10$. 


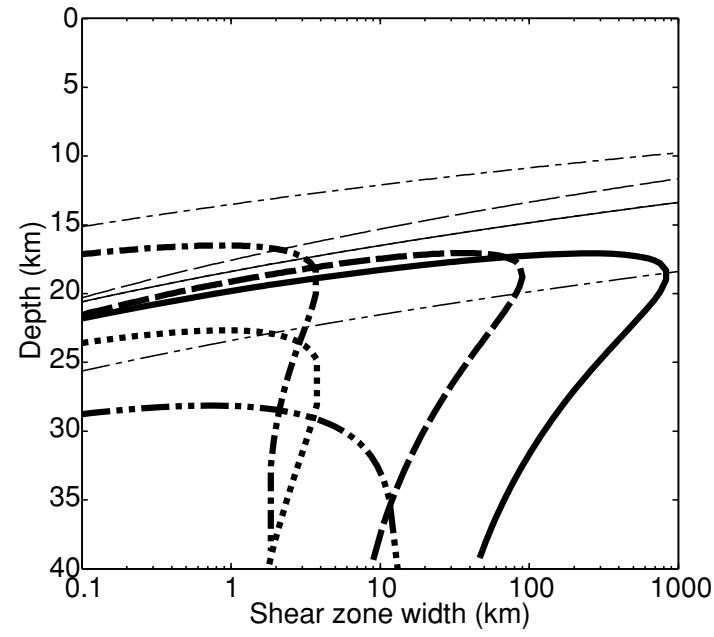

Fig. 5. Predictions of the conditions for which $R_{S}=10$ (thick lines) as a function of shear zone width $H$. The thin lines indicate the bottom edge of earthquakes ruptures. Models parameters are similar to Fig. 4 (repeated as solid lines) except: shear zone rheology is from $\mathrm{Pa}$ terson and Luan (long dashes); earthquake slip is $6 \mathrm{~m}$ (short dashes); the surface geotherm is $30 \mathrm{~K} / \mathrm{km}$ (dash-dots); rupture overshooting the brittle-ductile transition by $5 \mathrm{~km}$ (dash-double dots).

is possible. Here, I define $H_{m}$ as the shear zone thickness for which $R_{s}=10$.

The minimum shear zone thickness is a function not only of the shear zone model, but also of the earthquake model. In the reference case, I choose to consider a rather large earthquake, rupturing over a $12 \mathrm{~km}$ depth range with $3 \mathrm{~m}$ of slip. These values are inspired by the Izmit earthquake but are not meant to represent that or any other event in particular, only to give an idea of the magnitude of expected stress perturbations. Slip is assumed to be uniform for simplicity, but also because is provides an upper bound to the earthquake-induced stress perturbation. Moreover, the rupture zone is chosen to abut the brittle-ductile transition in order to maximize the stress perturbation at any level in the plastic lower crust. In Fig. 4, the rupture zone is indicated with a grey-shaded field. The depth interval of the rupture is fixed at $12 \mathrm{~km}$ so that the stress drop is constant. As a consequence, the model earthquake does not rupture the surface, which is justified for some, but not all major earthquakes. It is possible for a seismogenic rupture to penetrate dynamically into the plastic lower crust (e.g., Tse and Rice, 1986), as we will discuss later.

The stress perturbation on a vertical shear zone for this model earthquake is shown in Fig. 4(B). Immediately below the rupture, the stress perturbation is infinite. At this level $R_{s}>10$ is obviously verified regardless of the shear zone width, but this is an artifact of the simplistic slip distribution assumed. Below a few km underneath the brittleductile transition, $R_{S}$ depends strongly on the shear zone width (Fig. 4(C)). $R_{S}<10$ is indicated in Fig. 4 with the thick grey line. At any depth, $R_{S}<10$ requires that the thickness of the shear zone exceeds $\sim 100 \mathrm{~km}$. Such thickness is at odds with geological observations. Moreover, the stress perturbation decays rapidly with $x$, the lateral distance from the seismogenic fault (Fig. 2). Hence, for a shear zone of $100 \mathrm{~km}$ thickness, the stress perturbation is greatly overestimated by Eq. (5), and the actual $R_{S}$ is much less than shown here. The reference model of Fig. 4 is therefore not compatible with observations of postseismic slip. In the next section, I discuss how this discrepancy can be resolved.

\section{Discussion}

The foregoing shows that the expected strength of a plastic shear zone far exceeds earthquake-induced stress perturbations, except immediately below the earthquake rupture. In what follows, I modify the parameters of this model to investigate under what conditions the intensity of postseismic deformation is compatible with a quartzite rheology. For these alternative models, I do not present maps of shear zone strength, earthquake perturbations, and $R_{S}$ but only the minimum allowable shear zone thickness, $H_{m}$ (Fig. 5).

First, let us assume an alternative flow law for the shear zone rocks. Luan and Paterson (1992) have obtained another well-constrained flow law for wet quartzite. In particular, they obtain a stress exponent of 3.1 compared with 4 used by Hirth et al. (2001). Using their parameters reduces the minimum shear zone width to $\sim 20 \mathrm{~km}$, still uncomfortably high (Fig. 5, dashed line).

Increasing the stress drop, and thereby the magnitude of the stress perturbation, by a factor of two decreases $R_{S}$ by the same value, allowing shear zones that are only $\sim 2 \mathrm{~km}$ wide to reach postseismic velocities compatible with geodetic values (Fig. 5, dotted line). Increasing the stress drop is best justified by increasing the average earthquake slip to $6 \mathrm{~m}$. However, this implies a very large earthquake. Scaling relations for large earthquakes are strongly debated, but it is possible that slip is limited for strike-slip events, precluding $6 \mathrm{~m}$ slip (Romanowicz, 1992; Shaw and Scholz, 2001). Following the scaling law of Mai and Beroza (2000) for strike-slip earthquakes, $6 \mathrm{~m}$ slip implies a $M_{w}=7.8$ event. However, postseismic creep was observed for numerous smaller events, such as the 7.2 Landers earthquake and the 7.1 Hector Mine event.

The stress perturbation on a localized plastic shear zone would be increased if the rupture could penetrate below the brittle-ductile transition. Numerical models show that dynamic aspects of earthquake ruptures make this possible (Tse and Rice, 1986). If the rupture penetrates $5 \mathrm{~km}$ into the plastic domain the minimum shear zone thickness is still $10 \mathrm{~km}$ (Fig. 5, dash-double dots line), still larger than geological observations suggest. For larger overshoot, smaller shear zones are possible, but postseismic creep occurs only at great depth, which is at odds with kinematic inversion of postseismic creep transient (Bürgmann et al., 2002).

If stress perturbations can't be increased much more than assumed in the reference model, one must conclude that the model overestimates shear zone strength. It is possible that the rheology of quartzite is not appropriate for describing a plastic shear zone. Fabric development in the shear zone, including the segregation of weak phases and grain size reduction, may result in a weaker rock than studied in the laboratory. It may be that quartzite shear zones do not participate in postseismic creep, and that observations of postseismic creep indicate the presence of alternative composition, for instance calcite or hydrated phases. In particular, calcite is abundant and probably weaker than quartzite un- 
der natural conditions (Brodie and Rutter, 2000). However, uncertainties in calcite flow laws (Renner and Evans, 2002) make it difficult to incorporate calcite in this analysis.

Alternatively, the weakness of plastic shear zones may be explained by a thermal anomaly associated with the shear zone. Formation of localized plastic shear zones has been the subject of numerous studies (e.g., Hobbs et al., 1990; Montési and Zuber, 2002; Montési and Hirth, 2003; Regenauer-Lieb and Yuen, 2003). Adiabatic shear heating associated with the high strain rate of the shear zone may be needed to localize plastic creep (e.g., Regenauer-Lieb and Yuen, 1998) resulting in a higher temperature in the shear zone than in its surroundings. In the shear zone model presented above, this can be simulated by increasing the surface geotherm. A value of $30 \mathrm{~K} / \mathrm{km}$ allows postseismic deformation to be present in shear zones $2 \mathrm{~km}$ thick (Fig. 5 , dashed-dot line).

This study argues that in order to produce the observed intensity of postseismic deformation, shear zones must be anomalously weak. This may be due to structural or thermal effects. At first sight, this is incompatible with microstructural evidence for high stress in plastic shear zones (Küster and Stöckhert, 1999; Trepmann and Stöckhert, 2003). However, these rocks may have been very close to the brittle-ductile transition, where, as seen in Fig. 4, both high stresses and high stress perturbations are expected. Because of the simplicity of the slip distribution that I use here, it is not clear whether or not postseismic creep is expected at that depth level, but there is ample evidence for postseismic deformation abutting seismic rupture (e.g., Hsu et al., 2002), which indicates that earthquake-induced stress perturbations are comparable to rock strength in that region. Regardless, it is also clear that postseismic creep is not limited to this limited high-stress zone. In the majority of the depth range where postseismic creep is observed, pre-stresses are low.

\section{Summary}

Several GPS data sets show that as the result of an earthquake, the creep velocity of the aseismic plastic lower crust changes at least an order of magnitude. This indicates that the pre-earthquake stress is not more than a factor of 10 higher than the earthquake-induced stress perturbation, regardless of the nonlinearity of the creep laws. As the stress perturbation scales with the stress drop, this implies a surprisingly low strength of the ductile lower crust. Indeed, comparing these stress estimates with laboratory-derived flow laws, it appears that plastic shear zones should be too strong to allow the magnitude of postseismic creep transients that are now routinely observed. Various weakening processes have been proposed based on geological observations and theoretical models. To be successful, they must produce shear zones that are less than half as strong as wet quartzite, one of the weakest rocks tested in the laboratory.

The rough analysis in this paper is concerned only with order of magnitude estimates. The highest values of the stress perturbation estimates were retained and the weakest laboratory-derived rock rheology was selected, in an attempt to reconcile stress drop and postseismic velocities. Yet, laboratory-derived flow laws appear inconsistent with the magnitude of postseismic creep transients. The next step is to utilize a well documented event to produce more accurate stress transfer and material response models and constrain how much weaker than implied by laboratory the plastic lower crust is. Thus, it should be possible to constrain the weakening mechanism in that location. In time, this approach will yield a better knowledge of the strength of the lower crust that can then be fed back into rupture models for a more reliable estimate of seismic risks.

Acknowledgments. I am grateful to Shibazaki-san and the organizing committee for the invitation to participate in the symposium. This project benefited from many discussions with Greg Hirth, Jian Lin, Jeff McGuire, and Uri ten Brink at WHOI, and was supported by NSF grant EAR-0337678 and the J. Lamar Worzel Assistant scientist Fund. Roland Bürgmann and an anonymous reviewer helped me improve this manuscript.

\section{References}

Ambraseys, N., The seismic activity of the Marmara sea region over the last 2000 years, Bull. Seism. Soc. Am., 92, 1-18, 2002.

Brodie, K. H. and E. H. Rutter, Deformation mechanisms and rheology: Why marble is weaker than quartzite, J. Geol. Soc. London, 157, 10931096, 2000.

Brace, W. F. and D. L. Kohlstedt, Limits on lithospheric stress imposed by laboratory measurements, J. Geophys. Res., 85, 6248-6252, 1980.

Bürgmann, R., M. G. Kogan, V. E. Levin, C. H. Scholz, R. W. King, and G. M. Steblov, Rapid aseismic moment release following the 5 December, 1997 Kronotsky, Kamchatka, earthquake, Geophys. Res. Lett., 28, 1331-1334, 2001.

Bürgmann, R., S. Ergintav, P. Segall, E. H. Hearn, S. McClusky, R. E. Reilinger, H. Woith, and J. Zschau, Time-dependent afterslip on and deep below the İzmit earthquake rupture, Bull. Seism. Soc. Am., 92, 126-137, 2002.

Carter, N. L. and M. C. Tsenn, Flow properties of continental lithosphere, Tectonophysics, 136, 27-63, 1987.

Cowie, P. A. and C. H. Scholz, Physical explanation for the displacement length relationship of faults using a post-yield fracture mechanics model, J. Struct. Geol., 14, 1133-1148, 1992.

Evans, B. and D. L. Kohlstedt, Rheology of rocks, in Rock Physics and Phase Relations: A Handbook of Physical Constants, AGU Ref. Shelf 3, edited by T. J. Ahrens, pp. 148-165, American Geophysical Union, Washington, 1995.

Freed, A. M. and R. Bürgmann, Evidence of powerlaw flow in the Mojave Desert mantle, Nature, 430, 548-551, 2004.

Freed, A. M. and J. Lin, Delayed triggering of the 1999 Hector Mine earthquake by viscoelastic stress transfer, Nature, 411, 180-183, 2001.

Freymueller, J., R. Bürgmann, E. Calais, A. Freed, E. Price, and Denali Fault GPS Field Crew, An unparallel opportunity to study postseismic processes, EOS Trans. Am. Geophys. Union, 83, Fall Meet. Suppl., Abstract S72F-1365, 2002.

Hanks, T. C., Earthquake stress drops, ambient tectonic stresses, and stresses that drive plate motions, Pure Appl. Geophys., 115, 441-458, 1977.

Heki, K., S. Miyazaki, and H. Tsuji, Silent fault slip following an interplate thrust earthquake at the Japan trench, Nature, 386, 595-598, 1997.

Hirth, G., C. Teyssier, and W. J. Dunlap, An evaluation of quartzite flow laws based on comparisons between experimentally and naturally deformed rocks, Int. J. Earth Sci., 90, 77-87, 2001.

Hobbs, B. E., H.-B. Mühlhaus, and A. Ord, Instability, softening and localization of deformation, in Deformation Mechanisms, Rheology and Tectonics, Geol. Soc. Spec. Pub. 54, edited by R. J. Knipe and E. H. Rutter, 15-34, pp. 143-165, The Geological Society of London, London, 1990.

Hsu, Y.-J., N. Bechor, P. Segall, S.-B. Yu, L.-C. Kuo, and K.-F. Ma, Rapid afterslip following the 1999 Chi-Chi, Taiwan earthquake, Geophys. Res. Lett., 29, 10.1029/2002GL014967, 2002.

Hudnut, K. W., N. E. King, J. E. Galetzka, K. F. Stark, J. A. Behr, A. Aspiotes, S. van Wyk, R. Moffitt, S. Dockter, and F. Wyatt, Continuous GPS observations of postseismic deformation following the 16 October 1999 Hector Mine, California, Earthquake $\left(M_{w} 7.1\right)$, Bull. Seism. Soc. Am., 92, 1403-1422, 2002. 
Ida, Y., Cohesive forces across the tip of a longitudinal-shear crack and Griffith's specific surface energy, J. Geophys. Res., 77, 3796-3805, 1972.

Iio, Y. and Y. Kobayashi, Is the plastic flow uniformly distributed below the seismogenic region?, Tectonophysics, 364, 43-53, 2002.

Iio, Y., Y. Kobayashi, and T. Tada, Large earthquakes initiate by the acceleration of slips on the downward extensions of seismogenic faults, Earth Planet. Sci. Lett., 202, 337-343, 2002.

Kanamori, H. and D. L. Anderson, Theoretical basis of some empirical relations in seismology, Bull. Seism. Soc. Am., 65, 1073-1095, 1975.

Jónsson, S., P. Segall, R. Pedersen, and G. Björnsson, Post-earthquake ground movements correlated to pore-pressure transients, Nature, $\mathbf{4 2 4}$, 179-183, 2003.

Kohlstedt, D. L., B. Evans, and S. J. Mackwell, Strength of the lithosphere: Constraints imposed by laboratory experiments, J. Geophys. Res., 100, 17587-17602, 1995.

Küster, M. and B. Stöckhert, High differential stress and sublithostatic pore fluid pressure in the ductile regime-microstructural evidence for short-term post-seismic creep in the Sesia Zone, Western Alps, Tectonophysics, 303, 263-277, 1999.

Luan, F. C. and M. S. Paterson, Preparation and deformation of synthetic aggregates of quartz, J. Geophys. Res., 97, 97301-97320, 1992.

Mai, P. M. and G. Beroza, Source scaling properties from finite-fault rupture models, Bull. Seism. Soc. Am., 90, 604-615, 2000.

Marone, C. J., C. H. Scholz, and R. Bilham, On the mechanics of earthquake afterslip, J. Geophys. Res., 96, 8441-8452, 1991.

McClusky, S., S. Balassanian, A. Barka, C. Demir, S. Ergintav, I. Georgiev, O. Gurkan, M. Hamburger, K. Hurst, H. Kahle, K. Kastens, G. Kekelidze, R. King, V. Kotzev, O. Lenk, S. Mahmoud, A. Mishin, M. Nadariya, A. Ouzonis, D. Paradissis, Y. Peter, M. Prilepin, R. Reilinger, I. Sanli, H. Seeger, A. Tealeb, M. N. Toksöz, and G. Veis, Global positioning constraints on plate kinematics and dynamics in the eastern Mediterranean and Caucasus, J. Geophys. Res., 105, 5695-5719, 2000.

Melbourne, T. I., F. H. Webb, J. M. Stock, and C. Reigber, Rapid postseismic transients in subduction zones from continuous GPS, J. Geophys. Res., 107, 2241, doi:10.1029/2001JB000555, 2002.

Montési, L. G. J., Controls of shear zone rheology and tectonic loading on postseismic creep, J. Geophys. Res., 109, B10404, doi:10.1029/JB2003JB002925, 2004.

Montési, L. G. J. and G. Hirth, Grain size evolution and the rheology of ductile shear zones: From laboratory experiments to postseismic creep, Earth Planet. Sci. Lett., 211, 97-110, 2003.

Montési, L. G. J. and M. T. Zuber, A unified description of localization for application to large-scale tectonics, J. Geophys. Res., 107, doi:10.1029/2001JB000465, 2002.

Okada, Y., Internal deformation due to shear and tensile faults in a halfspace, Bull. Seism. Soc. Am., 82, 1018-1040, 1992.

Paterson, M. S., Problems in the extrapolation of laboratory data, Tectonophysics, 133, 33-43, 1987.

Peltzer, G., P. Rosen, F. Rogez, and K. Hudnut, Poroelastic rebound in fault step-overs cause by pore fluid flow, Science, 273, 1202-1204, 1996.

Peltzer, G., P. Rosen, F. Rogez, and K. Hudnut, Poro-elastic rebound along the Landers 1992 earthquake surface rupture, J. Geophys. Res., 103,
30131-30145, 1998.

Ramsay, J. G., Shear zone geometry, a review, J. Struct. Geol., 2, 83-89, 1980.

Regenauer-Lieb, K. and D. A. Yuen, Rapid conversion of elastic energy into shear heating during incipient necking of the lithosphere, Geophys Res. Lett., 58, 2737-2740, 1998.

Regenauer-Lieb, K. and D. A. Yuen, Modeling shear zones in geological and planetary sciences: Solid- and fluid-thermal-mechanical approaches, Earth Sci. Rev., 63, 295-349, 2003.

Renner, J. and B. Evans, Do calcite rocks obey the power-law creep equation?, in Deformation Mechanisms, Rheology and Tectonics: Current Status and Future Perspectives, Geol. Soc. Spec. Pub. 200, edited by S. de Meer, M. R. Drury, J. H. P. de Bresser, and G. M. Pennock, pp. 293-307, The Geological Society of London, London, 2002.

Romanowicz, B., Strike-slip earthquakes on quasi-vertical transcurrent faults: Inferences for general scaling relations, J. Geophys. Res., 19, 481-484, 1992.

Savage, J. C., Equivalent strike-slip earthquake cycle in half-space and lithosphere-asthenosphere Earth models, J. Geophys. Res., 95, 48734879, 1990.

Shaw, B. E. and C. H. Scholz, Slip-length scaling in large earthquakes: Observations and theory and implications for earthquake physics, Geophys. Res. Lett., 28, 2991-2994, 2001.

Shibazaki, B., H. Tanaka, H. Horikawa, and Y. Iio, Modeling slip processes at the deeper part of the seismogenic zone using a constitutive law combining friction and flow laws, Earth Planets Space, 54, 1211-1218, 2002.

Thatcher, W., Nonlinear strain buildup and the earthquake cycle on the San Andreas Fault, J. Geophys. Res., 88, 5893-5902, 1983.

Tödheide, K., Water at high temperature and pressure, in Water: A Comprehensive Treatise, edited by F. Franks, pp. 463-514, 1972.

Trepmann, C. and B. Stöckhert, Quartz microstructures developed during non-steady state plastic flow at rapidly decaying stress and strain rate, $J$. Struct. Geol., 25, 2035-2051, 2003.

Tse, S. T. and J. R. Rice, Crustal earthquake instability in relation to the depth variation of frictional slip properties, J. Geophys. Res., 91, 94529472, 1986.

Vauchez, A. and A. Tommasi, Wrench faults down to the asthenosphere Geological and geophysical evidence and thermo-mechanical effects, in Intraplate Strike-slip Deformation Belts, Geol. Soc. Spec. Pub. 210 , edited by F. Storti, R. E. Holdsworth, and F. Salvini, pp. 15-34, The Geological Society of London, London, 2003.

Yagi, Y., M. Kikuchi, and T. Nishimura, Co-seismic slip, postseismic slip, and largest aftershock associated with the 1994 Sanriku-haruka-oki, Japan, earthquake, Geophys. Res. Lett., 30, 2177, doi:10.1029/2003GL018189, 2003.

Yu, S.-B., Y.-J. Hsu, L.-C. Kuo, H.-Y. Chen, and C.-C. Liu, GPS measurement of postseismic deformation following the 1999 Chi-Chi, Taiwan earthquake, J. Geophys. Res., 108, doi:10.1029/2003JB002396, 2003.

L. G. J. Montési (e-mail: montesi@whoi.edu) 